\section{Brain, Behavior and Evolution}

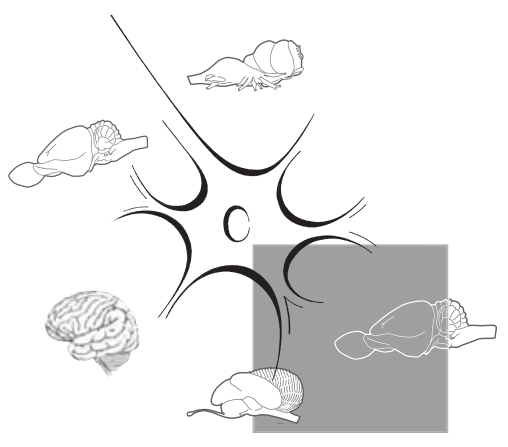

In a recent article in Nature Reviews Neuroscience, Kempermann [2012] proposed that adult neurogenesis in the dentate gyrus of mammals may function differently from the adult neurogenesis seen in the brains of nonmammals and, rather than representing a vestigial function compared to the widespread neurogenesis seen in nonmammals, is a co-opting of that process for a new purpose in mammals, namely the ability to adapt to a wide range of environments. He cites rats and humans as examples of species that possess that adaptability, species that are found in every ecological niche on earth. He correctly states that the dentate gyrus is not present in nonmammals in its mammalian form and hypothesizes that, with its appearance, a new ability to adapt developed. This ability varies among mammals, according to his hypothesis, with animals like bats and dolphins, who have limited or no neurogenesis in the dentate gyrus, showing less adaptability in their behavior than rats or humans.

This thesis is an interesting one, which will require much more data than are currently available to test, as Kempermann acknowledges. He does not discuss, however, data showing that adult neurogenesis in nonmammals is influenced by the same

\title{
Adult Neurogenesis in Mammals and Nonmammals
}

\author{
Commentary on Kempermann G (2012): New neurons for 'survival of the \\ fittest'. Nat Rev Neurosci 13:727-736
}

Alice Schade Powers

Stony Brook University, Stony Brook, N.Y., USA

processes as dentate gyrus neurogenesis is in mammals, i.e. by learning and cognitive stimulation. Thus, his paper does not acknowledge the existence of evidence that neurogenesis in widespread areas of the nonmammalian brain is subject to the same processes as neurogenesis in the dentate gyrus of mammals. For example, enriched environments enhance adult neurogenesis in nonmammals, just as Kempermann and others have shown in extensive studies of mammals [e.g., Kempermann et al., 1997; Nilsson et al., 1999; van Praag et al., 1999]. Mountain chickadees that live in the wild, where the environment is presumably richer, show more neurogenesis in the hippocampus than those that live in a laboratory setting [LaDage et al., 2010], and mountain chickadees that live in the laboratory and are allowed to cache seeds show more adult neurogenesis than those prevented from caching seeds [LaDage et al., 2010]. Painted turtles exposed to an enriched environment show more adult neurogenesis in the telencephalon, including the homologue of the hippocampus, the medial cortex, compared to those housed individually in tanks with little opportunity for stimulation [Powers and Hanusch, 2012]. After exposure to an enriched environment, there was an increase in the num- ber of new cells in the telencephalon of zebra fish [von Krogh et al., 2010], including the homologue of the hippocampus, the lateral pallium. In addition to effects on the hippocampal homologue in these nonmammals, neurogenesis typically increased in other areas of the telencephalon as well. The role of adult neurogenesis in song learning in birds is well-known [Goldman and Nottebohm, 1983; for a review, see Barnea and Pravosudov, 2011], and although it does not occur in the hippocampus, it does suggest that avian adult neurogenesis is playing a role in plasticity, as it does in mammals.

Thus, even with the modest amount of data now available, the widespread neurogenesis in nonmammalian vertebrates appears to have some of the same functions as the narrowly restricted neurogenesis in mammals. Kempermann [2012] specifically states that the new form of plasticity based in the dentate gyrus 'builds on ancient mechanisms' (p. 730). Thus, he might agree that these functions exist in nonmammals and yet wish to argue that the function of the dentate gyrus in mammals is 'a newly evolved form of plasticity' ( $p$. 730). If additional research confirms the findings in nonmammals, the parsimonious explanation would be that neurogene-

\section{KARGER}

E-Mail karger@karger.com

www.karger.com/bbe
C 2013 S. Karger AG, Base

0006-8977/13/0814-0206\$38.00/0
Alice Schade Powers

Stony Brook University

Department of Psychology

Stony Brook, NY 11794-2500 (USA)

E-Mail alice.powers@stonybrook.edu 
sis in nonmammals is serving the same purpose as it serves in mammals, in spite of its more widespread nature in nonmammals. Before adopting Kempermann's thesis, it will be necessary to demonstrate that the dentate gyrus mediates behaviors that are not present in nonmammalian species. Beyond that, it will be necessary to demonstrate that neurogenesis in the dentate gyrus mediates these behaviors.

As provocative as Kempermann's thesis is, the paper contains errors in his summary of neurogenesis in nonmammalian vertebrates. Kempermann provides a table summarizing the presence of adult neurogenesis in different animals (fig. 1). The table describes three categories for neurogenesis: no adult neurogenesis, few defined neurogenic regions, and widespread adult neurogenesis. In canaries, pigeons, snakes, and turtles, the table says that there are few defined neurogenic regions. In canaries and turtles, however, widespread neurogenesis occurs in the telencephalon, and this has been known for some time [canaries: Alvarez-Buylla et al., 1994; Boseret et al., 2007; turtles: Perez-Canellas et al., 1997; Font et al., 2001; Kesaraju and Milton, 2009]. Studies on pigeons and snakes have been published recently, and these groups also show widespread neurogenesis [pi- geons: Melleu et al., 2013; snakes: Holding et al., 2012].

In another column in the table, three other categories are listed: no specific hippocampal neurogenesis, neurogenesis in hippocampal equivalent, or distinct neurogenesis in the dentate gyrus. Here the table states that canaries, zebra finches, pigeons, lizards, snakes, turtles, and frogs have no specific hippocampal neurogenesis, but all of these species do have adult neurogenesis in the medial wall of the telencephalon, in a region considered to be homologous to at least some part of the hippocampus of mammals [canaries: Alvarez-Buylla et al., 1994; Boseret et al., 2007; zebra finches: Lee et al., 2007; Pytte et al., 2007; pigeons: Melleu et al., 2013; lizards: Perez-Canellas and Garcia-Verdugo, 1996; Font et al., 2001; turtles: Perez-Canellas et al., 1997; frogs: Raucci et al., 2006 - see their fig. 8C]. It might be that the author would dispute the hippocampal equivalence of the medial wall of the telencephalon to the hippocampus of mammals, but most authors agree with this position [Atoji and Wild, 2004; Butler and Hodos, 2005]. Kempermann points out that the equivalent of the dentate gyrus itself in nonmammals is not known and that an exact homologue may not ex- ist, but his table addresses hippocampal equivalents, not dentate gyrus equivalents. In addition, the table says that no hippocampal neurogenesis is seen in the hippocampus of teleost fish, but in the caption to figure 2, the author correctly states that adult neurogenesis is found in the lateral wall of the telencephalon in bony fish, in a region believed to be homologous to the hippocampus, both structurally and functionally [Butler, 2000; Rodriguez et al., 2002].

Perhaps the central question in the comparative analyses of adult neurogenesis is why it occurs only in the hippocampus and olfactory bulb in mammals but in widespread areas of the telencephalon in birds and reptiles and in even more widespread areas of the brain in fish and amphibians. Kempermann suggests that the difference between mammals and nonmammals is due to the development of a new function for the dentate gyrus. Further research on both mammals and nonmammals will be needed to resolve this issue, but for the moment, the evidence suggests that the functions seen in nonmammals have not been lost in mammals, but rather remodeled and concentrated in a limited region of the telencephalon.

\section{References}

Alvarez-Buylla A, Ling CY, Yu WS (1994): Contribution of neurons born during embryonic, juvenile, and adult life to the brain of adult canaries: regional specificity and delayed birth of neurons in the song-control nuclei. J Comp Neurol 347:233-248.

Atoji Y, Wild JM (2004): Fiber connections of the hippocampal formation and septum and subdivisions of the hippocampal formation in the pigeon as revealed by tract tracing and kainic acid lesions. J Comp Neurol 475:426461.

- Barnea A, Pravosudov V (2011): Birds as a model to study adult neurogenesis: bridging evolutionary, comparative and neuroethological approaches. Eur J Neurosci 34:884-907.

Boseret G, Ball G, Balthazart J (2007): The microtubule-associated protein doublecortin is broadly expressed in the telencephalon of canaries. J Chem Neuroanat 33:140-154.

Butler AB (2000): Topography and topology of the teleost telencephalon: a paradox resolved. Neurosci Lett 293:95-98.

-Butler AB, Hodos W (2005): Comparative Vertebrate Neuroanatomy: Evolution and Adaptation, ed 2. Hoboken, Wiley.
Font E, Desfilis E, Perez-Canellas MM, GarciaVerdugo JM (2001): Neurogenesis and neuronal regeneration in the adult reptilian brain. Brain Behav Evol 58:276-295.

Goldman SA, Nottebohm F (1983): Neuronal production, migration, and differentiation in a vocal control nucleus of the adult female canary brain. Proc Natl Acad Sci USA 80:23902394.

Holding ML, Frazier JA, Taylor EN, Strand CR (2012): Experimentally altered navigational demands induce changes in the cortical forebrain of free-ranging northern pacific rattlesnakes (Crotalus o. oreganus). Brain Behav Evol 79:144-154.

Kempermann G (2012): New neurons for 'survival of the fittest'. Nat Rev Neurosci 13:727-736.

-Kempermann G, Kuhn HG, Gage FH (1997): More hippocampal neurons in adult mice living in an enriched environment. Nature 386: 493-495.

Kesaraju S, Milton SL (2009): Preliminary evidence of neuronal regeneration in the anoxia tolerant vertebrate brain. Exp Neurol 215: 401-403.
LaDage LD, Roth TC, Fox RA, Pravosudov VV (2010): Ecologically relevant spatial memory use modulates hippocampal neurogenesis. Proc R Soc B 277:1071-1079.

Lee DW, Fernando G, Peterson RS, Allen TA, Schlinger BA (2007): Estrogen mediation of injury-induced cell birth in neuroproliferative regions of the adult zebra finch brain. Dev Neurobiol 67:1107-1117.

Melleu FF, Santos TS, Lino-de-Oliveira C, Marino-Neto J (2013): Distribution and characterization of doublecortin-expressing cells and fibers in the brain of the adult pigeon (Columba livia). J Chem Neuroanat 47:5770.

- Nilsson M, Perfilieva E, Johansson U, Orwar O, Eriksson PS (1999): Enriched environment increases neurogenesis in the adult rat dentate gyrus and improves spatial memory. J Neurobiol 39:569-578.

-Perez-Canellas MM, Font E, Garcia-Verdugo JM (1997): Postnatal neurogenesis in the telencephalon of turtles: evidence for nonradial migration of new neurons from distant ventricular proliferative zones to the olfactory bulbs. Dev Brain Res 101:125-137. 
Perez-Canellas MM, Garcia-Verdugo JM (1996): Adult neurogenesis in the telencephalon of a lizard: a $\left[{ }^{3} \mathrm{H}\right]$-thymidine autoradiographic and bromodeoxyuridine immunocytochemical study. Dev Brain Res 93:49-61.

Powers AS, Hanusch B (2012): Effect of enriched environment on adult neurogenesis in turtles (Chrysemys picta) (abstract 500.15). Soc Neurosci Abstr 42:157.
Pytte CL, Gerson M, Miller J, Kim JR (2007): Increasing stereotypy in adult zebra finch song correlates with a declining rate of neurogenesis. Dev Neurobiol 67:1699-1720.

-Raucci F, DiFiore MM, Pinelli C, D’Aniello B, Luongo L, Polese G, Rastogi RK (2006): Proliferative activity in the frog brain: a PCNAimmunohistochemistry analysis. J Chem Neuroanat 32:127-142.

-Rodriguez F, Lopez JC, Vargas JP, Gomez Y, Broglio C, Salas C (2002): Conservation of spatial memory function in the pallial forebrain of reptiles and ray-finned fishes. J Neurosci 22: 2894-2903. van Praag H, Kempermann G, Gage FH (1999): Running increases cell proliferation and neurogenesis in the adult mouse dentate gyrus. Nat Neurosci 2:266-270

von Krogh K, Sorensen C, Nilsson G, Overli O (2010): Forebrain cell proliferation, behavior, and physiology of zebrafish, Danio rerio, kept in enriched or barren environments. Physiol Behav 101:32-39. 